\title{
What They Want and What They Get: Self-Reported Motives, Perceived Competence, and Relatedness in Adolescent Leisure Activities
}

\author{
Ingrid Leversen, ${ }^{1}$ Anne G. Danielsen, ${ }^{2}$ Bente Wold, ${ }^{1}$ and Oddrun Samdal ${ }^{1}$ \\ ${ }^{1}$ Department of Health Promotion and Development, Faculty of Psychology, University of Bergen, P.O. Box 7807, \\ 5020 Bergen, Norway \\ ${ }^{2}$ Faculty of Humanities, Social Sciences and Education, University of Tromsø, 9037 Tromsø, Norway
}

Correspondence should be addressed to Ingrid Leversen, ingrid.leversen@iuh.uib.no

Received 6 December 2011; Revised 13 April 2012; Accepted 25 April 2012

Academic Editor: Cheryl Dissanayake

Copyright (C) 2012 Ingrid Leversen et al. This is an open access article distributed under the Creative Commons Attribution License, which permits unrestricted use, distribution, and reproduction in any medium, provided the original work is properly cited.

This study explored the extent to which adolescents' motives for leisure activity participation are related to their perceptions of competence and relatedness in different kinds of activities and aimed to provide new insight into boys' and girls' leisure experiences and their motivational orientations for activity participation. These proposed associations were based on previous empirical work and the theoretical frameworks of motive disposition approach and were tested in a nationally representative sample of Norwegian adolescents $(N=3273)$ aged 15 and 16 years $(51.8 \%$ boys $)$ from the World Health Organization's crosssectional survey, Health Behaviour in School-Aged Children 2005/06. The findings in the current study supported the hypothesis regarding matched correlations between specific motives and specific outcomes in that the adolescents seem to get (perceived competence and relatedness) what they want (competence and social motives) within leisure activities. Furthermore, the analysis using structural equation modeling indicated different motivational orientations in types of leisure activity participation between girls and boys, although the mediating effects of leisure activity participation in different types of activities were not significant.

\section{Introduction}

Participation in leisure activities, and especially in organized activities, has been considered in several studies to be a possible contributor to well-being and good mental health [1-6]. Leisure activity participation constitutes a huge and important part of young people's lives and may provide adolescents with unique developmental opportunities for socialization and learning [5-7]. The likelihood for adolescents to have such positive developmental experiences, however, may vary across individuals and across different activities. The current study assesses the association between adolescents' self-reported participation in leisure activities, their motives for participation, and their perceptions of competence and relatedness in the activities.

Adolescents may perceive various motives for participation in leisure activities, and different motives may underlie the selection of specific activities. A frequent motive reported by adolescents for participation in both sport and art activities is socialization with peers $[8,9]$. According to Bowlby [10], human beings are born with innate psychobiological needs that motivate them to seek proximity to significant others (attachment figures). As a fundamental motivation in itself, the need to belong and form social attachments should stimulate goal-directed activity to satisfy it [11]. People tend to seek out interpersonal contacts and develop possible relationships until they have reached a minimum level of social contact and relatedness. Ryan and Deci [12] also describe relatedness as a universal psychosocial need that includes a person's strivings to relate to and care for others, to feel that those others are relating authentically to one self, and to feel a satisfying and consistent involvement with the social world more generally. During adolescence, peers become increasingly more important. Leisure activities represent a core arena for being social with peers and friends 
as they provide opportunities of shared experiences, positive feedback from others, and may reinforce friendships between peers and relationships with adults [13]. Such experiences may further contribute to one's identity as an important and valued member of a group or community.

Competence has been found to be another common motive for activity participation. The first manifestation of competence is present at early childhood reflected in the infant's natural tendency toward curiosity and exploratory play [14]. This is a process that continues in adulthood and is commonly triggered in competence-relevant settings revealing concerns such as self-presentation concerns, affiliating concerns, and self-worth concerns [15]. According to Bandura [16], feelings of personal competence are related to self-perceptions of efficacy regarding one's ability in dealing with distinct social domains and are seen as proximal and direct predictors of psychological motivation, affect, and behaviors. Leisure activity settings provide an excellent opportunity for adolescents to experience the feeling to be good at certain skills and activities, to get challenged, and to develop new skills. The experience of competence may make individuals gain psychological rewards and to feel that they can act effectively and bring about goals [12]. In previous studies, feelings of competence in activities have been found to be related to both higher general need satisfaction and well-being $[8,17-20]$.

The motives adolescents report for engaging in leisure activities may have a direct impact on the positive outcomes that are experienced within the leisure domain. Expression of competence motives and social motives may moreover induce individuals to achieve this through leisure participation. What adolescents want (and the degree that they want it) in leisure activities may thus be predictive of what they actually get.

A way of understanding the role of motives and perceived outcomes of leisure activities may be offered by the motive disposition approach [21]. Here, the motives are identified as achievement motives (the desire to improve one's skills while successfully interacting with the environment) and affiliation motives (the desire to establish and/or maintain warm and friendly interpersonal relations). These are thought to be stable dispositions that vary from person to person. An assumption of the motive disposition approach is that high-achievement-motivated individuals differ from lowachievement-motivated individuals in their (higher) capacity for gaining satisfaction from seeking and attaining the feeling of competence [21]. Furthermore, Richer and colleagues [22] found that the relationship between social factors and motivation was mediated by the perception of relatedness and that this meditational relationship was moderated by the strength of the participant's dispositional need for relatedness. Similar relationships have also been found for competence [23, 24]. In a recent paper, where both motive disposition approach framework and self-determination theory were applied [25], one of the hypotheses tested was that adolescents motive for achievement would uniquely predict concurrent competence of need-satisfaction, and that the motive for affiliation would uniquely predict concurrent relatedness of need-satisfaction. The four studies included in their paper were not directed toward any specific setting. The hypothesis tested was based on the assumption that being motivated towards a certain need ("wanting") often leads to "having" the experience they want. In all four studies, this hypothesis was supported. Previous research thus acknowledges the importance and value of matching specific motives with specific perceived outcomes. The current study therefore sets out to examine the match between competence motives and perceptions of competence, and between social motives and perceptions of relatedness within the setting of adolescents' leisure activities.

There is a substantial literature that demonstrates the positive developmental opportunities in organized leisure activities, and some studies have also found experiences to vary with the kind of activity in which one participates [4, 26-28]. Furthermore, differences in leisure experiences may be affected by the adolescent's gender. Various studies have shown strong gender differences in adolescents' choices and preferences in leisure activity participation [29-34]. Girls have been found to be more involved than boys in individual sports and creative activities such as dancing, music, and drama, whereas boys have been found to spend more time than girls on team sport activities and computerrelated activities [30, 32, 35-39]. Studies focusing on the sport domain have found that boys are oriented towards activities that have a more competitive nature (such as soccer) $[40,41]$, whereas girls orient themselves more towards feminine sports focused on aesthetics and rhythms (such as gymnastics and aerobics). It is therefore reasonable to conclude that boys and girls potentially have different motivational orientations in seeking specific activities to achieve competence and relatedness and that such gender differences need to be studied in more detail.

Few studies have identified the relationship between adolescents' motives for general leisure activity participation and perceived outcomes of their participation. The purpose of the current study was therefore to investigate gender differences in associations between competence and social motives for leisure activity participation, actual leisure activity participation, and perceptions of competence and relatedness. Finally, we wanted to explore whether leisure activity participation in team sport activities, individual sport activities, music and art activities, and civic activities had mediating effects on the relationship between motives and perceived outcomes, and to identify possible similarities and differences of motivational patterns for boys and girls. To our knowledge, no study has yet looked at the mediating effect of participating in different types of leisure activities. The suggested mechanism was that specific competence motives and social motives in leisure activity participation would increase participation in certain types of activities, depending on the adolescents' gender. Furthermore, the increased participation was hypothesized to be related to perceptions of increased competence and/or relatedness. The link between level of leisure activity participation and level of positive experiences has been observed in previous studies on adolescents $[42,43]$. Earlier studies have also found that factors such as breadth and intensity of activity participation are both associated with positive developmental outcomes, 
such as psychological competencies, and positive peer context (for an overview, see [44]). The assumed mechanisms are that increased participation provides individuals with a wider range of activities related to growth experiences, increased levels of socialization experiences, and larger support networks. In the present study, this assumption would imply that the more the boys and girls participate in the activities they seek based on what they want to achieve, the more likely they are to achieve what they want if participation in the activity offers the relevant opportunities for them. The current investigation aimed to increase our knowledge of the specification of the relationships.

\section{Method}

2.1. Sample. The sample was obtained using a clustered sampling procedure with school class as the sampling unit [45]. As part of the World Health Organization's survey, Health Behaviour in School-Aged Children 2005/06, a representative sample of 3273 Norwegians aged 15 and 16 years participated in the study. They comprised 1537 from grade 10 (mean age 15.48 years) and 1736 from the grade 1 upper secondary class (mean age 16.51 years). There were approximately equal numbers of boys and girls (51.8\% boys). One class per school participated in the study. Of the invited schools, $70 \%$ chose to participate in the study (30\% of schools refused); in the actively participating schools, the student response rate was $83 \%$. Overall, taking the nonparticipating schools into account, the response rate at student level was $58 \%$.

2.2. Procedures. The data collection procedures were considered by the Regional Committees for Medical Research Ethics and approved by the Norwegian Social Science Data Services Privacy Ombudsman for Research. The data were collected in accordance with a standardized protocol [45] through an individual questionnaire to all students in the selected classes. The survey was conducted in December 2005. Informed consent was given from the school principal and the students. A passive consent procedure from parents was followed, requiring parents to return a letter declining consent to the teacher if they did not want their child to participate. The teachers were given instructions on how to administer the survey. Questionnaires were distributed and filled out during an ordinary school hour (45 minutes). Students were informed that participation was voluntary and that their responses were anonymous. The questionnaires were returned to the University of Bergen for coding and analysis. All the data were treated anonymously.

\subsection{Measures}

2.3.1. Competence Motive and Social Motive in Leisure Activity Participation. Competence motive and social motive were each measured by three items. The items comprised a checklist of reasons why people like doing different kinds of leisure activities, and the participants rated the importance of these reasons for themselves ("very important," "fairly important," and "not important"). These were reasoned to be indicators of the adolescents' perceived motivation for leisure activity participation. The three items measuring competence motives were "to learn new things," "to do something interesting," and "to do something I can manage," and the three items measuring social motives were "to see my friends," "to make new friends," and "to be with others who like this activity". The items were based on a previous version that measured motives for participating in sports [46]. Cronbach's alpha was .56 for the competence motive subscale, and .62 for the social motive subscale. According to standard criteria for reliability, these alphas are relatively low [47]. However, as noted by Cronbach [47], given a small number of items, low alphas can underestimate scale item intercorrelations that are the basis for internal consistency. With short scales, the adequacy of the underlying measurement model may be more indicative of the quality of construct measurement than internal consistency [48].

\subsubsection{Perceptions of Competence and Relatedness in Leisure} Activity Participation. To assess perceptions of competence and relatedness in leisure activity, two subscales were used. There were three items for perceived competence (e.g., "People I know tell me I am good at the activities I do in my leisure time") and three items for perceived relatedness (e.g., "The people I spend time with in my leisure time activities I consider to be my friends"). The respondents were asked to think about the leisure activities that they liked to do best. The adolescents responded on a five-point Likert scale from "strongly agree" to "strongly disagree." Cronbach's alpha in the present study was .70 for the competence subscale, and .79 for the relatedness subscale.

2.3.3. Leisure Time Activities. The measure of leisure time activities comprised a list of 22 leisure activities. The adolescents reported how often they participated in the different activities ("two to three times a month or more seldom" (1), "about once a week" (2), "two times a week or more" (3), or "do not do this activity" (0)). For the analysis, the four response categories were recorded to include only weekly activities $(0=0,1=0,2=1,3=2)$. This was done to capture the frequency of the activities that adolescents participated in on a regular basis, and these were considered more likely to be structured activities. The activities were divided into four groups; team sport activities (e.g., soccer, handball, and basketball), individual sport activities (e.g., athletics, cycling, swimming, and boxing/kickboxing), music and art activities (e.g., music lessons, band, dancing, and theatre/drama), and civic activities (e.g., church activities, scouting, and volunteering) [37]. A sum score for each group was used in the analyses.

2.3.4. Family Affluence Scale (FAS). The FAS measures the families' material wealth; previous work supports the use of the FAS as an indicator of socioeconomic status [49]. Family affluence is calculated using the following four questions: "Does your family have a car or a van?" (family car ownership) (no/yes, one/yes, two or more); "How many computers does your family own?” (computer ownership) 
(none/one/two/more than two); "Do you have your own bedroom for yourself?" (bedroom occupancy) (no/yes); "During the past 12 months, how many times did you travel away on holiday with your family?" (family holidays) (not at all/once/twice/more than twice) [49]. The four indicators were combined to produce a linear composite score, with the FAS ranging from 0 (lowest affluence) to 9 (highest affluence).

2.3.5. Analyses. All descriptive analyses, Pearson correlations, independent samples $t$-tests, and linear regression analyses were performed using IBM SPSS Statistics version 19 (SPSS Inc., n.d.). Structural equation modeling (SEM) using AMOS program 18.0 [50] was undertaken to explore the interrelationships between the study variables and possible mediation effects. For the SEM analysis in AMOS, all variables were treated as observed variables. Family affluence was included as a control variable in the model with direct paths to perceptions of competence and relatedness and the four types of activity participation. The covariance matrix was analyzed by applying maximum likelihood estimation (ML). Goodness of model fit was judged based on two fit indices: the comparative fit index (CFI; values of .90 or greater indicate that the model provides an adequate fit to the data) and the root-mean-square error of approximation (RMSEA; values of .08 or less indicate an adequate fit; good fit $>.05)[51,52]$.

To test for gender differences and to explore whether boys and girls would have different motivational orientations with regard to type of activity participation, we used multigroup analyses [53], which tested whether the model was invariant across genders. The main focus of the multigroup analyses in the present paper was to test whether the path coefficients between the variables were invariant across the two groups. Through these analyses, alternate models, each of which constrained one key path or covariance as equal for boys and girls, was tested, and then their model fit was compared with that of the base SEM for which every parameter was freely estimated within gender. For each model whose fit declined relative to the base SEM (CFI changing $\geq .002$, [54]), we concluded that there was a gender difference in the respective path tested.

To assess whether the study variables of activity participation in the four different types of activities were mediators and carried the influence of the independent variables to the dependent variables, we used the Sobel test [55]. These tests were performed by calculating the regression weights and standard errors of the path between the independent variable (predictor) and the mediator, and between the mediator and the dependent variable (outcome).

\section{Results}

3.1. Competence Motives and Social Motives in Leisure Activity Participation. Descriptive analyses of self-reported competence motives and social motives showed heterogeneity in the importance of the different motives, with $46 \%$ to $77 \%$ of adolescents rating them as "very important" (shown

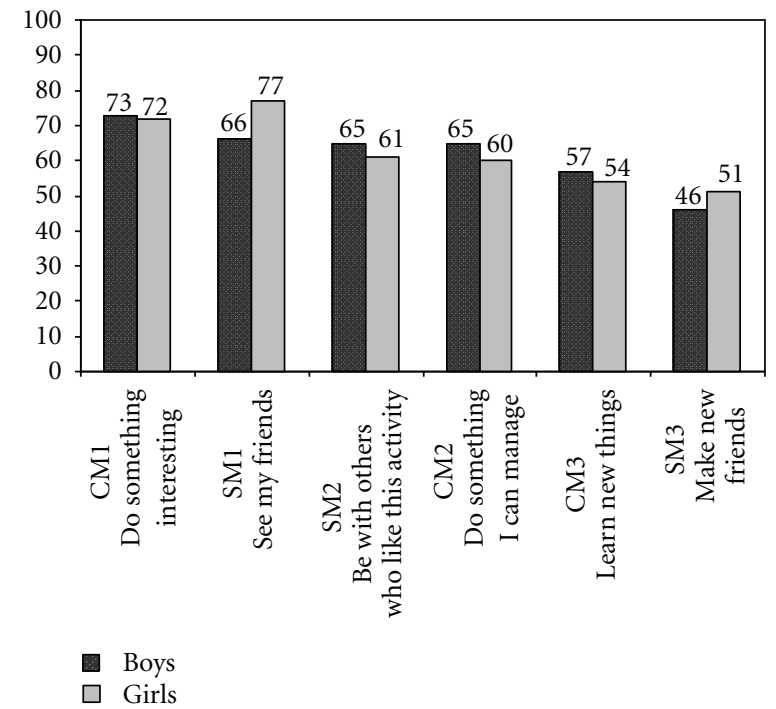

Figure 1: Percentages of the adolescents rating the competence and social motives items of leisure activity participation "very important" by gender, and chi-square tests of differences between genders. $\mathrm{CM}=$ competence motives; $\mathrm{SM}=$ social motives.

in Figure 1). The most significant gender differences were found for social motive items. In particular, seeing friends $\left(\chi^{2}=45.27, P<.001\right)$ and making friends $\left(\chi^{2}=\right.$ 18.06, $P<.001)$ were significantly more important for girls than for boys. Significantly more boys reported most competence motives to be important; however, the gender differences were minor. Independent $t$-tests of the sum scores (see Table 1) revealed that girls reported significantly higher levels of social motives (Cohen's $d$ effect size $=.13$ ) than boys. There was no significant difference on the total competence motive score. Boys reported higher importance in competence motives than social motives (Cohen's $d$ effect size $=.18$ ), whereas there were no significant differences between the motives for girls. However, it is important to emphasize that differences amounting to less than 0.20 standard deviation units are regarded small [56].

\subsection{Perceptions of Competence and Relatedness in Leisure} Activity Participation. As indicated in Figure 2, initial descriptive analyses on perceptions of competence and relatedness within leisure activity participation showed that the responses were quite homogeneous; girls and boys reported generally high levels of competence and relatedness in their leisure activity participation ("strongly agree" response percentages ranged between $61 \%$ and $91 \%$ on all items). Significantly more boys than girls thought they were good at the activities they did $\left(\chi^{2}=69.14, P<.001\right)$ and felt cared for in their activities $\left(\chi^{2}=28.48, P<.001\right)$. Independent $t$-tests of the sum scores (see Table 1 ) revealed that boys reported significantly higher perceived competence than girls ( $t$ (3057) $=3.55, P<.001$, Cohen's $d=.17$ ), although this difference was small. There was no significant gender difference in the perceptions of relatedness $(t(3033)=-.71, P=.48)$. Both boys and girls reported significantly higher relatedness than 
TABle 1: Descriptive statistics (mean, standard deviation (SD), number ( $n$ ), and $t$-test of differences between boys and girls.

\begin{tabular}{|c|c|c|c|c|c|c|c|c|}
\hline \multicolumn{9}{|c|}{ Descriptives } \\
\hline \multirow{2}{*}{ Study variables } & \multicolumn{3}{|c|}{ Boys } & \multicolumn{3}{|c|}{ Girls } & \multirow[b]{2}{*}{$t$-test } & \multirow[b]{2}{*}{ Cohen's $a$} \\
\hline & Mean & $\mathrm{SD}$ & $n$ & Mean & $\mathrm{SD}$ & $n$ & & \\
\hline Competence motives & 2.61 & .41 & 1557 & 2.59 & .39 & 1502 & 1.68 & .06 \\
\hline Social motives & 2.53 & .47 & 1545 & 2.58 & .41 & 1504 & $-3.32^{* *}$ & .13 \\
\hline Team sport participation & 1.14 & 1.31 & 1408 & .65 & 1.09 & 1365 & $10.63^{* * *}$ & .41 \\
\hline Individual sport participation & 1.87 & 1.88 & 1335 & 1.30 & 1.49 & 1295 & $8.72^{* * *}$ & .34 \\
\hline Music and art participation & .54 & 1.28 & 1341 & 1.06 & 1.56 & 1336 & $-9.5^{* * *}$ & .38 \\
\hline Civic activity participation & .27 & .68 & 1348 & .29 & .69 & 1345 & -.90 & .04 \\
\hline Perceived competence & 4.02 & .74 & 1581 & 3.92 & .71 & 1493 & $3.55^{* * *}$ & .17 \\
\hline Perceived relatedness & 4.19 & .72 & 1564 & 4.21 & .73 & 1496 & -.71 & .03 \\
\hline
\end{tabular}

${ }^{* *} P<.01, * * * P<.001$.

TABLE 2: Bivariate correlations between the study variables, with boys below the diagonal and girls above the diagonal.

\begin{tabular}{lcccccccc}
\hline Study variables & $(1)$ & $(2)$ & $(3)$ & $(4)$ & $(5)$ & $(6)$ & $(7)$ & $(8)$ \\
\hline (1) Competence motives & - & $.48^{* * *}$ & .05 & $.07^{*}$ & $.13^{* * *}$ & $.06^{*}$ & $.26^{* * *}$ & $.11^{* * *}$ \\
(2) Social motives & $.55^{* * *}$ & - & .05 & .05 & .03 & $.09^{* *}$ & $.18^{* * *}$ & $.24^{* * *}$ \\
(3) Team sport participation & $.07^{*}$ & $.11^{* * *}$ & - & $.15^{* * *}$ & $-.08^{* *}$ & .00 & $.16^{* * *}$ & $.14^{* * *}$ \\
(4) Individual sport participation & $.09^{* *}$ & $.11^{* * *}$ & $.22^{* * *}$ & - & $.07^{* *}$ & $.11^{* *}$ & $.17^{* * *}$ & $.13^{* * *}$ \\
(5) Music and art participation & .05 & .01 & -.02 & $.06^{*}$ & - & $.18^{* * *}$ & $.15^{* * *}$ & .04 \\
(6) Civic activity participation & .05 & $.08^{* *}$ & -.00 & $.09^{* *}$ & $.23^{* * *}$ & - & $.15^{* * *}$ & $.12^{* * *}$ \\
(7) Perceived competence & $.31^{* * *}$ & $.23^{* * *}$ & $.17^{* * *}$ & $.14^{* * *}$ & .05 & .05 & - & $.49^{* * *}$ \\
(8) Perceived relatedness & $.27^{* * *}$ & $.29^{* * *}$ & $.14^{* * *}$ & $.11^{* * *}$ & .05 & .04 & $.62^{* * *}$ & - \\
\hline
\end{tabular}

${ }^{*} P<.05,{ }^{* *} P<.01,{ }^{* * *} P<.001$.

competence (for boys: Cohen's $d=.23$, and for girls: Cohen's $d=.40)$. Differences ranging from 0.10 to 0.50 standard deviations are regarded small to moderate [56].

3.3. Gender Differences in Leisure Activity Participation. Independent $t$-tests (Table 1 ) of activity levels in the four different groups of activities showed that girls participated significantly more often in music and art activities than boys (Cohen's $d$ effect size $=.38$ ), whereas boys participated significantly more often than girls in team sports (Cohen's $d$ effect size $=.41$ ) and in individual sports (Cohen's $d$ effect size $=.34)$. There were no significant gender differences in civic activities.

3.4. Relationships between Study Variables. Bivariate correlation analyses on the study variables, split by gender, showed that competence motives and social motives were positively related to perceived competence and relatedness for both boys and girls (see Table 2). For girls, the correlations between activity participation and perceived competence were significant and positive for all four types of activities, whereas for boys, the only significant correlation was found for team and individual sports. Similar results were found for perceived relatedness, although there were no significant correlations between music and art participation and perceived relatedness for girls. The analyses between competence motive and activity participation revealed only relatively weak positive correlations with team and individual sport, and slightly higher correlations between social motives and team sport, individual sport, and civic activities for boys. The strongest correlation for girls was found between competence motives and music and art participation $(r=$ $.13)$.

Two linear regression analyses were also conducted to examine the unique contribution of competence motive and social motive in predicting perceptions of competence satisfaction and relatedness [57] (see Table 3). Competence motives predicted higher significant variance in competence satisfaction than did social motives. Social motives predicted higher significant variance in perception of relatedness than did competence motives. However, for boys, the effect of competence motive on relatedness $(\beta=.16)$ was almost as strong as the effect of social motive on relatedness $(\beta=.21)$, indicating that both motives may have a similar effect on perception of relatedness for boys.

3.5. SEM Analysis. Inspection of the multivariate skewness and kurtosis revealed some nonnormality in the data. All outliers (z-scores with higher than three standard deviations above the mean, observed only for the four activity groups (174 cases)) were therefore excluded from the SEM analyses. The measurement model was tested for boys and girls separately. The model fit was RMSEA $=.066$ and CFI $=$ .973 for boys, and RMSEA $=.082$ and CFI $=.947$ for 
TABLE 3: Results from the linear regression analyses testing the contribution of competence motive and social motive on the outcome variables (perceptions of competence and relatedness) by gender.

\begin{tabular}{|c|c|c|c|c|c|c|}
\hline \multirow{3}{*}{ Predictors } & \multicolumn{6}{|c|}{ Perceived competence } \\
\hline & \multicolumn{3}{|c|}{ Boys } & \multicolumn{3}{|c|}{ Girls } \\
\hline & $\beta$ & $t$ & $R^{2}$ & $\beta$ & $t$ & $R^{2}$ \\
\hline Competence motive & .27 & $9.08^{* * *}$ & & .23 & $7.83^{* * *}$ & \\
\hline \multirow{2}{*}{ Social motive } & .09 & $2.91^{* *}$ & .10 & .07 & $2.24^{*}$ & .07 \\
\hline & \multicolumn{6}{|c|}{ Perceived relatedness } \\
\hline \multirow[t]{2}{*}{ Predictors } & & Boys & & & Girls & \\
\hline & $\beta$ & $t$ & $R^{2}$ & $\beta$ & $t$ & $R^{2}$ \\
\hline Competence motive & .16 & $5.36^{* * *}$ & & -.02 & -.65 & \\
\hline Social motive & .21 & $6.95^{* * *}$ & .10 & .26 & $8.82^{* * *}$ & .06 \\
\hline
\end{tabular}

${ }^{*} P \leq .05,{ }^{* *} P \leq .01,{ }^{* * *} P \leq .001$.

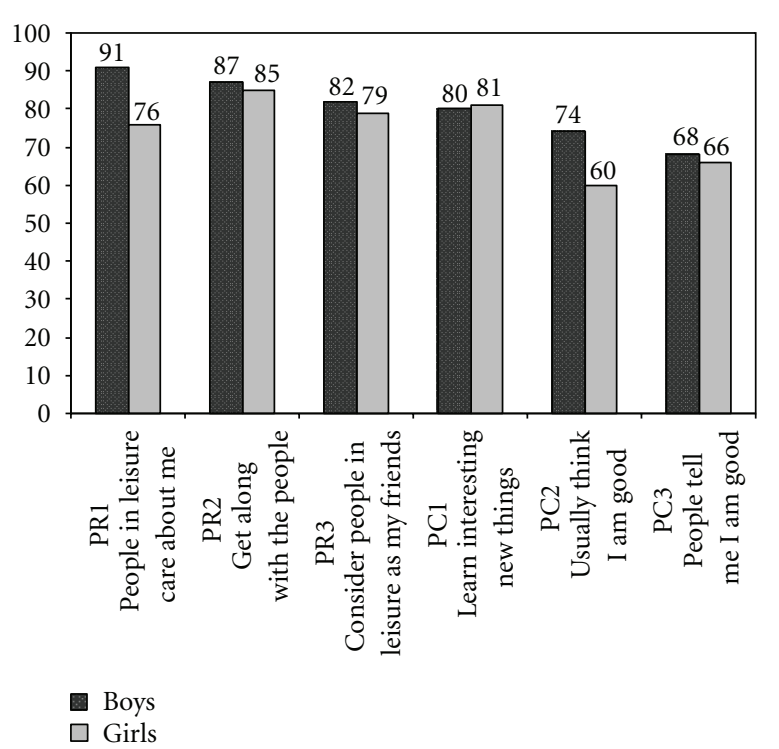

Figure 2: Percentages of the adolescents rating the items of perceived competence and relatedness in leisure activity participation from "agree" to "strongly agree" by gender. PC = perception of competence; $\mathrm{PR}=$ perception of relatedness.

girls. According to Byrne (2001), these may be regarded as acceptable fit indices [51]. It has been suggested that RMSEA below .05 indicates good fit $[52,58]$, but that values as high as .08 may be acceptable. However, the CFI was close to .95 , which indicates good fit [58]. There were relatively high correlations observed between the error covariance of perception of competence and the error covariance of relatedness and between competence motive and social motive.

3.5.1. Multigroup Comparisons and Mediation. The structural model was tested using a multigroup analysis approach. The direct paths tested were the effects between motives and need satisfaction, the effects between motives and leisure activity participation, and the effects between leisure activity participation and perceived outcomes. Finally, the indirect effect was tested for each of the two motives in leisure activity participation on perceptions of competence and relatedness, mediated by leisure activity participation in the four different types of activities.

Based on the relatively high correlations observed between the error covariance of perceived competence and relatedness in the measurement model, and similar findings in previous studies (e.g., [59]), they were allowed to covary in the structural model. The competence motive and social motive were also allowed to covary in the structural model, based on the observations of relatively high correlation between the two in the measurement model. Theoretically, this makes sense, because both these types of motives may be recognized as intrinsic, compared with other extrinsic motives (e.g., $[8,14-17,60]$. The goodness-of-fit indexes for the multigroup structural model testing the two groups (boys and girls) in the same model were CFI $=.965$ and RMSEA $=.048(90 \% \mathrm{CI}=.040-.058)$, which may be regarded as a good fit of the model. Figure 3 displays the standardized regression weights and correlations for boys and girls of this structural model. Some, but not all, of the results were significant at the $P<.05$ level. The path coefficients were invariant across the two groups with the exception of four paths (with CFI changing $\geq .002$ ) [56]. Three direct effects were significantly stronger for girls than for boys: the effect of team sport participation $(\beta=.16, P<.001)$ and civic activity participation $(\beta=.10, P<.001)$ on perceived relatedness and the effect of competence motive on music and art participation $(\beta=.14, P<.001)$. The direct effect of competence motive on perceived relatedness $(\beta=.15, P<$ .001) was significantly stronger for boys than for girls. The squared multiple correlations, for boys, were 14 (perceived competence) and .13 (perceptions of relatedness), and for girls, .13 and .12 .

To test the significance of the mediator effects, Sobel tests were performed for the parameters with significant direct paths [55]. The results of the Sobel tests showed that the study variables of participation in team sport, individual sport, music and art activities, and civic activities did not function as significant mediators, for either boys or girls. 

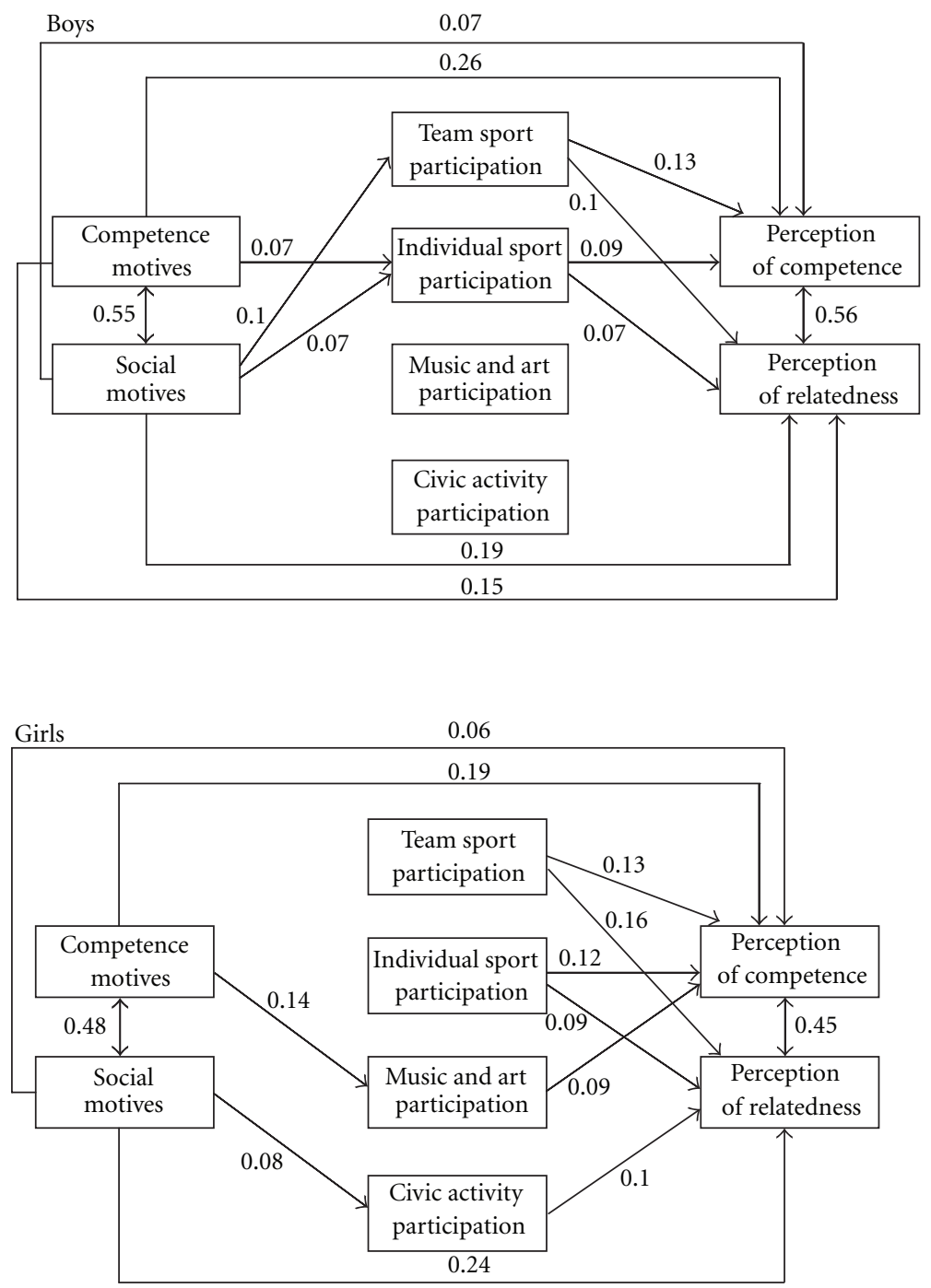

FIGURE 3: Structural model of the relation between motives in leisure activity participation and Perceptions of competence and relatedness within participation, for boys and girls, with standardized regression and correlations. All drawn paths were significant at the $P<.05$ level.

\section{Discussion}

The present study investigated motives for leisure activity participation as potentially predicting factors that may contribute to perceptions of positive outcomes of participation in leisure activities. This was done to investigate the unique relationship between each motive and the perception of the corresponding outcome, and to explore how well the expressed motives corresponded with the adolescents' actual perceptions of outcomes of leisure participation. The findings support the match hypothesis based on the theoretical and empirical assumptions in the motive disposition approach $[21,25]$ in that the adolescents seem to get (perceived competence and relatedness) what they want (competence and social motives) within leisure activities. There were positive associations between competence motives and perceived competence, and between social motives and perceptions of relatedness. This indicates that the more important the achievements of competence and/or social interactions are to individuals, the more they experience competence and relatedness in leisure activity participation. The study thus adds to the previous research by demonstrating the importance of looking into the specific motives and perceived outcomes among adolescents to achieve a more accurate picture of their leisure experiences. Knowledge about these experiences in adolescents may furthermore be important in facilitating leisure activity participation that may contribute to their positive development.

Even though we found distinct contributions of competence motives on perceptions of competence, and of social motives on perceptions of relatedness for both boys and girls, the results suggest that the correlation between the social motive and perceptions of relatedness was weaker for boys than for girls. For boys, competence motives had a similar effect to social motives on relatedness. One reason may be that competence and social interaction in leisure activities are more interrelated for boys than they are for girls. For instance, boys may experience relatedness more 
implicitly because they seek participation and competence enhancement in more social and group-related activities, such as team sports. Team sports have been associated with higher social skills, interpersonal relationships, and teamwork than individual sports [61]. Perceptions of relatedness may therefore potentially be a natural experience during such social activities. Girls, on the other hand, demonstrated a unique contribution of the social motive to perceptions of relatedness. Regardless of the activity they participate in, girls may be more conscious of their social needs and focus more on the intimacy of social relations. This reasoning is supported by Cross and Madson [62] who hypothesized that women, more than men, seek to maintain a sense of relatedness and connectedness with close others and are more sensitive to their emotions. In the study of socialization of gender roles, Helgeson [63] also argues that a focus on or orientation towards other people (communion) is something that is characteristically feminine. In the present study, girls also rated social motives as slightly more important than boys, although these gender differences were only minor, and socializing with peers was reported to be rather important for both boys and girls.

The results of the current study support previous research that has demonstrated clear gender differences in activity participation [31, 33, 36-38]. Boys participated significantly more often than girls in team and individual sport activities, whereas girls were more involved with music and art activities than boys. Furthermore, girls who reported high motivation for competence participated significantly more often in music and art activities, whereas boys seemed to seek sport activities to meet the motives for social interactions and, to some degree, for competence. These findings correspond with previous research showing that boys and girls often have different preferences in leisure activity participation [30-35]. Moreover, motives in previous studies have also been found to differ between activities. Ryan and colleagues [19] found Tae Kwon Do participants to be higher in enjoyment and competence motives and lower in body-related motives and to show better adherence than aerobics participants. They argued that different types of sport and exercise may have different appeal on individuals, depending on their motives. Adolescents may thus possibly seek different kinds of activities to meet their expressed motives.

In the current study, the correlations between the social interaction and the competence motives, respectively, and participation in the four different types of activities in the current study were, however, relatively weak for both boys and girls. It may be that there are factors other than expressed motives that explain their participation in different kinds of activities. One factor could be that adolescents conform to gender-stereotypical expectations of activity participation, rather than following their motives. Another reason for these weak correlations may be that motives for competence and social interaction may make boys and girls participate in a certain activity, as hypothesized, without necessarily leading to increased participation in similar activities within the same activity group (e.g., music and art). This is basically what was measured in the current study because participation level in each activity type comprised several activities with relatively few categories of frequency in each activity.

A further interesting finding was that, for girls, participation in all four types of activity was significantly correlated with higher perceived competence, whereas for boys, only the team and individual sports led to higher perceived competence. This may indicate that girls may achieve increased competence in almost any activity (as long as they are motivated), and that boys only achieve increased competence in activities that, based on previous studies, may be perceived as typical boy activities. For example, within sport activities, girls' participation in masculine sports and activities has been found to be more acceptable than boys' participation in feminine sports and activities [41, 64]. Furthermore, previous research on gender-typed activities suggests that social changes have opened doors for girls to participate in traditionally masculine activities [34]. It may therefore be easier for girls to enter a broader range of activities and to achieve positive experiences in doing so.

In the present study, it was hypothesized that reporting high importance of competence and/or social motives would be related to higher levels of participation (to meet those underlying needs), which would then lead to perceptions of higher competence and relatedness. This would then imply a mediation effect of motives on perceived outcomes of leisure activity participation. The path model also purposely differentiated between four types of leisure activities to investigate possible different motivational orientations between boys and girls. The structural equation model showed that the strength of relations between motives in leisure activity participation and actual participation levels and between participation levels and perceptions of competence and relatedness varied between activity types and gender. Some of the direct significant paths suggested mediation effects of participation (for boys in team and individual sports participation, between social motive and perceived relatedness; for girls in music and art participation, between competence motive and perceived competence; for civic participation, between social motive and perceived relatedness). However, Sobel tests showed that participation in the four types of activities had no significant mediation effect on any of the relationships between specific motives and specific outcomes, for boys or girls. The lack of significant mediation effects may indicate that the type of activities adolescents participate in and how often they participate in those activities are not the most important factors for the perceptions of competence and relatedness within leisure activities. It would seem that what they recognize as important to achieve (their motives) within their activity participation is even more essential for their actual positive experiences than participation in a certain type of activity. This may guide adolescents' leisure participation, leading them to choose activities that they have an interest in and for which they have a talent.

However, there may be other explanations and interpretations for the lack of mediating effect of leisure activity participation found in the current analyses. Many of the participants in this study were involved in different kinds of activities simultaneously. The activity groups were therefore 
not mutually exclusive and could have been a confounding factor in the analyses, possibly hiding significant mediation effects, and thereby the potentially different motivational orientations between boys and girls. As adolescents often participated in more than one activity and often in different types of activities, the data could not provide information about which activities were of most importance to them. Some activities may be more self-defining than others [8], and, within the same activity context, identity experiences may also vary considerably between individuals [65]. Another methodological issue is that the perceptions of competence and relatedness were measured in general leisure activities, not in specific activities. We could therefore not know exactly which activity they were thinking of when they responded to these measurements, leaving it to be a measure of perceptions of competence and relatedness in adolescents' activity participation in general. Future research should therefore direct the indicators of perceived outcomes, as well as the motivation to participate, towards particular activities or groups of activities.

In addition to the limitations related to the methodological issues, the analyses in the study were based on crosssectional data, so causal relationships between the variables of participation motives, leisure activity participation, and perceived outcomes could not be determined. These relationships may thus be driven by reverse or bidirectional causal processes, and outcomes and motivations may influence each other. The rather large sample size may have influenced model fit indexes and significance of weak relationships. Caution is therefore needed when interpreting the results.

The participants in this study were 15 and 16 years of age. For future research, the inclusion of a wider age range would be valuable. Investigation of possible changes in motives for leisure activity participation and perceived outcomes of leisure activities from childhood to adolescence would be central to increase our knowledge and awareness of why individuals participate in leisure activities and the possible motivational differences between age groups. Moreover, given the positive relationship between leisure activity participation and well-being, it is of interest to study how motives and the positive outcomes in leisure activities relate to adolescents' continuation with the activity.

\section{Conclusion}

The main results support the relevance of investigating the links between what motivates adolescents to participate in leisure activities and the specific positive outcomes within activity participation. The Norwegian adolescents under investigation showed, in general, high levels of perceptions of competence and relatedness in leisure activity participation, and this was positively predicted by their competence and social motives and by participation in the different types of activities. Our hypothesis about matched motives (competence and social interaction) and perceived outcomes (competence and relatedness) was therefore supported. This finding also provides additional support for the motive disposition approach and previous findings based on this theoretical approach $[21,25]$. In the present study, the context of adolescents' leisure activity participation was the focus of attention with regard to our match hypothesis, and the findings may thus be an important contribution to the field of adolescent leisure research. The results from the SEM analyses indicated that there may be different motivational orientations in leisure activity participation for girls and boys, although the mediating effects of leisure activity participation were not significant.

Implications for Practice. The present study demonstrates that leisure activity participation may be an important arena for adolescents to experience competence and relatedness. Research shows that many adolescents typically drop out of organized activities and then spend more time hanging out with friends or playing computer games. Fewer organized activities may also be available for adolescents as they get older, and in many of the activities, the focus on prestige, winning, and promoting the most skilled participants becomes stronger with increasing age, leaving less room for participants who are not among the top ten. Making more organized activities available for older adolescents may therefore be an important way to increase the well-being and developmental opportunities of adolescents. The findings of the current study also suggest that it is important to consider how to motivate adolescents and help them find activities where they may achieve positive outcomes. Highly motivated participation may positively predict positive outcomes, which also may encourage adolescents to maintain consistent participation and thereby prevent dropout. This may be a challenging task for practitioners who organize and run the activities, but one that is also likely to have great benefits for the development and well-being of children and adolescents.

\section{Acknowledgments}

This research was supported by funding through the Research Programme on Public Health from the Research Council of Norway. Health Behaviour in School-Aged Children (HBSC) is an international study carried out in collaboration with WHO/EURO. The International Coordinator of the HBSC survey was Candace Currie, and the Data Management Centre Manager was O. Samdal. The 2005/06 survey was conducted by the Principal Investigator in Norway. For details, see http://www.hbsc.org/. The authors would like to thank the principals, teachers, and students for their participation in this project.

\section{References}

[1] L. L. Caldwell, "Leisure and health: why is leisure therapeutic?" British Journal of Guidance \& Counselling, vol. 33, no. 1, pp. 726, 2005.

[2] D. M. Casey, M. N. Ripke, and A. C. Huston, "Activity participation and the well-being of children and adolescents in the context of welfare reform," in Organized Activities as Contexts of Development: Extracurricular Activities, AfterSchool and Community Programs, J. L. Mahoney, R. W. Larson, and J. S. Eccles, Eds., pp. 65-84, Lawrence Erlbaum Associates, Mahwah, NJ, USA, 2005. 
[3] D. Coleman and S.-E. Iso-Ahola, "Leisure and health: the role of social support and self-determination," Journal of Leisure Research, vol. 25, no. 2, pp. 111-128, 1993.

[4] A. C. Fletcher, P. Nickerson, and K. L. Wright, "Structured leisure activities in middle childhood: links to well-being," Journal of Community Psychology, vol. 31, no. 6, pp. 641-659, 2003.

[5] R. W. Larson, "Toward a psychology of positive youth development," American Psychologist, vol. 55, no. 1, pp. 170-183, 2000.

[6] J. L. Mahoney, R. W. Larson, J. S. Eccles, and H. Lord, “Organized activities as development contexts for children and adolescents," in Organized Activities as Contexts of Development: Extracurricular Activities, After-School and Community Programs, J. L. Mahoney, R. W. Larson, and J. S. Eccles, Eds., pp. 3-22, Lawrence Erlbaum Associates, Mahwah, NJ, USA, 2005.

[7] J. L. Mahoney and H. Stattin, "Leisure activities and adolescent antisocial behavior: the role of structure and social context," Journal of Adolescence, vol. 23, no. 2, pp. 113-127, 2000.

[8] J. A. Fredricks, C. J. Alfeld-Liro, L. Z. Hruda, J. S. Eccles, H. Patrick, and A. M. Ryan, "A qualitative exploration of adolescents' commitment to athletics and the arts," Journal of Adolescent Research, vol. 17, no. 1, pp. 68-97, 2002.

[9] H. Patrick, A. M. Ryan, C. Alfeld-Liro, J. A. Fredricks, L. Z. Hruda, and J. S. Eccles, "Adolescents' commitment to developing talent: the role of peers in continuing motivation for sports and the arts," Journal of Youth and Adolescence, vol. 28, no. 6, pp. 741-763, 1999.

[10] J. Bowlby, The Making and Breaking of Qffectional Bonds, Tavistock, London, UK, 1979.

[11] R. F. Baumeister and M. R. Leary, "The need to belongdesire for interpersonal attachments as a fundamental human motivation," Psychological Bulletin, vol. 117, no. 3, pp. 497529, 1995.

[12] R. M. Ryan and E. L. Deci, "Self-determination theory and the facilitation of intrinsic motivation, social development, and well-being," American Psychologist, vol. 55, no. 1, pp. 68-78, 2000.

[13] J. S. Eccles, B. L. Barber, M. R. Stone, and J. E. Hunt, "Extracurricular activities and adolescent development," Journal of Social Issues, vol. 59, no. 4, pp. 865-889, 2003.

[14] R. W. White, "Motivation reconsidered: the concept of competence," Psychological Review, vol. 66, no. 5, pp. 297-333, 1959.

[15] C. S. Dweck, “The development of ability conceptions," in The Development of Achievement Motivation, A. Wigfield and J. S. Eccles, Eds., pp. 57-88, Academic Press, San Diego, Calif, USA, 2002.

[16] A. Bandura, Self-Efficacy: The Exercise of Control, W. H. Freeman, New York, NY, USA, 1997.

[17] C. M. Fredrick and R. M. Ryan, "Differences in motivation for sport and exercise and their relations with participation and mental health," Journal of Sport Behavior, vol. 16, no. 3, pp. 124-146, 1993.

[18] D. Markland and D. K. Ingledew, "Exercise participation motives: a self-determination theory perspective," in Intrinsic Motivation and Self-Determination in Exercise in Sport, M. S. Hagger and N. L. D. Chatzisarantis, Eds., pp. 23-34, Human Kinetics, Champaign, Ill, USA, 2007.

[19] R. M. Ryan, C. M. Frederick, D. Lepes, N. Rubio, and K. M. Sheldon, "Intrinsic motivation and exercise adherence," International Journal of Sport Psychology, vol. 28, no. 4, pp. 335-354, 1997.
[20] M. R. Weiss and L. Williams, "The why of youth sport involvement: a developmental perspective on motivational processes," in Developmental Sport and Exercise Psychology: A Lifespan Perspective, M. R. Weiss, Ed., pp. 223-268, Fitness Information Technology, Morgantown, WVa, USA, 2004.

[21] D.C. McClelland, Human Motivation, Cambridge University Press, New York, NY, USA, 1985.

[22] S. F. Richer, C. Blanchard, and R. J. Vallerand, "A motivational model of work turnover," Journal of Applied Social Psychology, vol. 32, no. 10, pp. 2089-2113, 2002.

[23] J. M. Harackiewicz, C. Sansone, and G. Manderlink, "Competence, achievement orientation, and intrinsic motivation: a process analysis," Journal of Personality and Social Psychology, vol. 48, no. 2, pp. 493-508, 1985.

[24] J. Schüler, K. M. Sheldon, and S. M. Fröhlich, "Implicit need for achievement moderates the relationship between competence need satisfaction and subsequent motivation," Journal of Research in Personality, vol. 44, no. 1, pp. 1-12, 2010.

[25] K. M. Sheldon and J. Schüler, "Wanting, having, and needing: integrating motive disposition theory and self-determination theory," Journal of Personality and Social Psychology, vol. 101, no. 5, pp. 1106-1123, 2011.

[26] D. M. Hansen, R. W. Larson, and J. B. Dworkin, "What adolescents learn in organized youth activities: a survey of selfreported developmental experiences," Journal of Research on Adolescence, vol. 13, no. 1, pp. 25-55, 2003.

[27] R. W. Larson, D. M. Hansen, and G. Moneta, "Differing profiles of developmental experiences across types of organized youth activities," Developmental Psychology, vol. 42, no. 5, pp. 849-863, 2006.

[28] D. M. Hansen, W. P. Skorupski, and T. L. Arrington, "Differences in developmental experiences for commonly used categories of organized youth activities," Journal of Applied Developmental Psychology, vol. 31, no. 6, pp. 413-421, 2010.

[29] U. Athenstaedt, G. Mikula, and C. Bredt, "Gender role selfconcept and leisure activities of adolescents," Sex Roles, vol. 60, no. 5-6, pp. 399-409, 2009.

[30] M. Fitzgerald, A. P. Joseph, M. Hayes, and M. O’Regan, "Leisure activities of adolescent schoolchildren," Journal of Adolescence, vol. 18, no. 3, pp. 349-358, 1995.

[31] M. Hilbrecht, J. Zuzanek, and R. C. Mannell, "Time use, time pressure and gendered behavior in early and late adolescence," Sex Roles, vol. 58, no. 5-6, pp. 342-357, 2008.

[32] R. W. Larson and S. Verma, "How children and adolescents spend time across the world: work, play, and developmental opportunities," Psychological Bulletin, vol. 125, no. 6, pp. 701736, 1999.

[33] C. West and D. H. Zimmerman, "Doing gender," Gender \& Society, vol. 1, no. 2, pp. 125-151, 1987.

[34] S. M. McHale, J. Y. Kim, S. Whiteman, and A. C. Crouter, "Links between sex-typed time use in middle childhood and gender development in early adolescence," Developmental Psychology, vol. 40, no. 5, pp. 868-881, 2004.

[35] J. S. Eccles and B. L. Barber, "Student council, volunteering, basketball, or marching band: what kind of extracurricular involvement matters?" Journal of Adolescent Research, vol. 14, no. 1, pp. 10-43, 1999.

[36] D. L. Schmalz and D. L. Kerstetter, "Girlie girls and manly men: children's stigma consciousness of gender in sports and physical activities," Journal of Leisure Research, vol. 38, no. 4, pp. 536-557, 2006.

[37] J. E. Jacobs, M. K. Vernon, and J. S. Eccles, "Activity choices in middle childhood: the roles of gender, self-beliefs, and parents' influence," in Organized Activities as Contexts of Development: 
Extracurricular Activities, After-School and Community Programs, J. L. Mahoney, R. W. Larson, and J. S. Eccles, Eds., pp. 235-254, Lawrence Erlbaum Associates, Mahwah, NJ, USA, 2005.

[38] B. J. Hirsch, J. G. Roffman, N. L. Deutsch, C. A. Flynn, T. L. Loder, and M. E. Pagano, "Inner-City youth development organizations: strengthening programs for adolescent girls," The Journal of Early Adolescence, vol. 20, no. 2, pp. 210-230, 2000.

[39] S. Pedersen and E. Seidman, "Contexts and correlates of out-of-school activity participation among low-income urban adolescents," in Organized Activities as Contexts of Development: Extracurricular Activities, After-School and Community Programs, J. L. Mahoney, R. W. Larson, and J. S. Eccles, Eds., pp. 85-109, Lawrence Erlbaum Associates, Mahwah, NJ, USA, 2005.

[40] E. Metheny, Connotations of Movement in Sport and Dance, William C. Brown, Dubuque, Iowa, USA, 1965.

[41] B. A. Riemer and M. E. Visio, "Gender typing of sports: an investigation of Metheny's classification," Research Quarterly for Exercise and Sport, vol. 74, no. 2, pp. 193-204, 2003.

[42] D. M. Hansen and R. W. Larson, "Amplifiers of developmental and negative experiences in organized activities: dosage, motivation, lead roles, and adult-youth ratios," Journal of Applied Developmental Psychology, vol. 28, no. 4, pp. 360-374, 2007.

[43] H. W. Marsh and S. Kleitman, "Extracurricular school activities: the good, the bad, and the nonlinear," Harvard Educational Review, vol. 72, no. 4, pp. 464-514, 2002.

[44] A. Bohnert, J. Fredricks, and E. Randall, "Capturing unique dimensions of youth organized activity involvement: theoretical and methodological considerations," Review of Educational Research, vol. 80, no. 4, pp. 576-610, 2010.

[45] C. Roberts, J. Freeman, O. Samdal et al., "The health behaviour in school-aged children (HBSC) study: methodological developments and current tensions," International Journal of Public Health, vol. 54, pp. 140-150, 2009.

[46] B. Wold and L. Kannas, "Sport motivation among young adolescents in Finland, Norway and Sweden," Scandinavian Journal of Medicine and Science in Sports, vol. 3, no. 4, pp. 283291, 1993.

[47] L. J. Cronbach, "Coefficient alpha and the internal structure of tests," Psychometrika, vol. 16, no. 3, pp. 297-334, 1951.

[48] E. J. Pedhazur and L. P. Schmelkin, Measurement, Design, and Analysis: An Integrated Approach, Lawrence Erlbaum Associates, Hillsdale, NJ, USA, 1991.

[49] C. Currie, M. Molcho, W. Boyce, B. Holstein, T. Torsheim, and M. Richter, "Researching health inequalities in adolescents: the development of the Health Behaviour in School-Aged Children (HBSC) family affluence scale," Social Science \& Medicine, vol. 66, no. 6, pp. 1429-1436, 2008.

[50] J. L. Arbuckle, Amos 18.0 User's Guide, Amos Development Corporation, Crawfordville, Fla, USA, 2009.

[51] B. Byrne, Structural Equation Modeling with AMOS: Basic Concepts, Applications, and Programming, Lawrence Erlbaum Associates, Mahwah, NJ, USA, 2001.

[52] M. W. Browne and R. Cudeck, "Alternative ways of assessing model fit," in Testing Structural Equation Models, K. A. Bollen and J. S. Long, Eds., pp. 136-162, Sage, Beverly Hills, Calif, USA, 1993.

[53] B. M. Byrne, "Testing for multigroup invariance using AMOS graphics: a road less traveled," Structural Equation Modeling, vol. 11, no. 2, pp. 272-300, 2004.
[54] A. W. Meade, E. C. Johnson, and P. W. Braddy, "Power and sensitivity of alternative fit indices in tests of measurement invariance," Journal of Applied Psychology, vol. 93, no. 3, pp. 568-592, 2008.

[55] K. J. Preacher and G .J. Leonardelli, "Calculation of the Sobel Test: an interactive calculation tool for mediation tests," Kristopher J. Preacher, Vanderbilt University, 2011, http:/quantpsy.org/sobel/sobel.htm.

[56] J. Cohen, Statistical Power Analysis for the Behavioral Sciences, Lawrence Erlbaum, Hillsdale, NJ, USA, 2nd edition, 1988.

[57] J. Cohen, P. Cohen, S. G. West, and L. Aiken, Applied Multiple Regression/Correlation Analysis for the Behavioral Sciences, Lawrence Erlbaum Associates, Mahwah, NJ, USA, 3rd edition, 2003.

[58] L. T. Hu and P. M. Bentler, "Cutoff criteria for fit indexes in covariance structure analysis: conventional criteria versus new alternatives," Structural Equation Modeling, vol. 6, no. 1, pp. $1-55,1999$.

[59] M. H. Véronneau, R. F. Koestner, and J. R. Z. Abela, "Intrinsic need satisfaction and well-being in children and adolescents: an application of the self-determination theory," Journal of Social and Clinical Psychology, vol. 24, no. 2, pp. 280-292, 2005.

[60] C. P. Stuntz and M. R. Weiss, "Achievement goal orientations and motivational outcomes in youth sport: the role of social orientations," Psychology of Sport and Exercise, vol. 10, no. 2, pp. 255-262, 2009.

[61] D. M. Hansen and R. W. Larson, "The Youth Experiences Survey 1.0: instrument development and testing," University of Illinois, 2002, http://www.youthdev.illinois.edu/Documents/YESreport.pdf.

[62] S. E. Cross and L. Madson, "Models of the self: self-construals and gender," Psychological Bulletin, vol. 122, no. 1, pp. 5-37, 1997.

[63] V. S. Helgeson, "Prototypes and dimensions of masculinity and femininity," Sex Roles, vol. 31, no. 11-12, pp. 653-682, 1994.

[64] D. E. Boyle, N. L. Marshall, and W. W. Robeson, "Gender at play: fourth-grade girls and boys on the playground," American Behavioral Scientist, vol. 46, no. 10, pp. 1326-1345, 2003.

[65] J. D. Coatsworth, E. H. Sharp, L. A. Palen, N. Darling, P. Cumsille, and E. Marta, "Exploring adolescent self-defining leisure activities and identity experiences across three countries," International Journal of Behavioral Development, vol. 29, no. 5, pp. 361-370, 2005. 


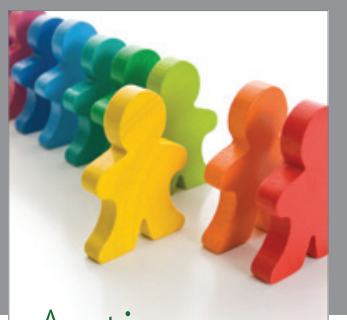

Autism

Research and Treatment
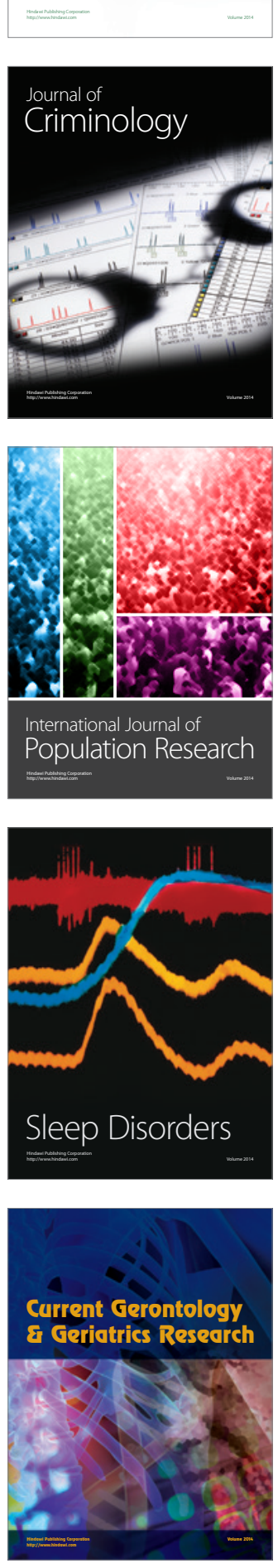
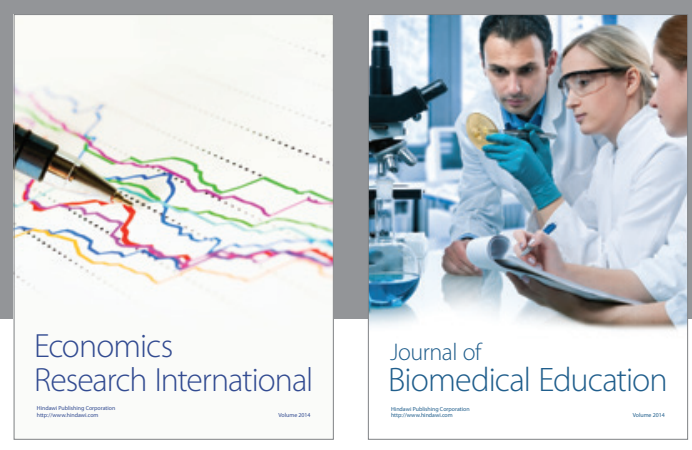

Journal of

Biomedical Education

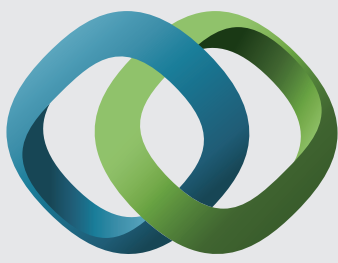

\section{Hindawi}

Submit your manuscripts at

http://www.hindawi.com
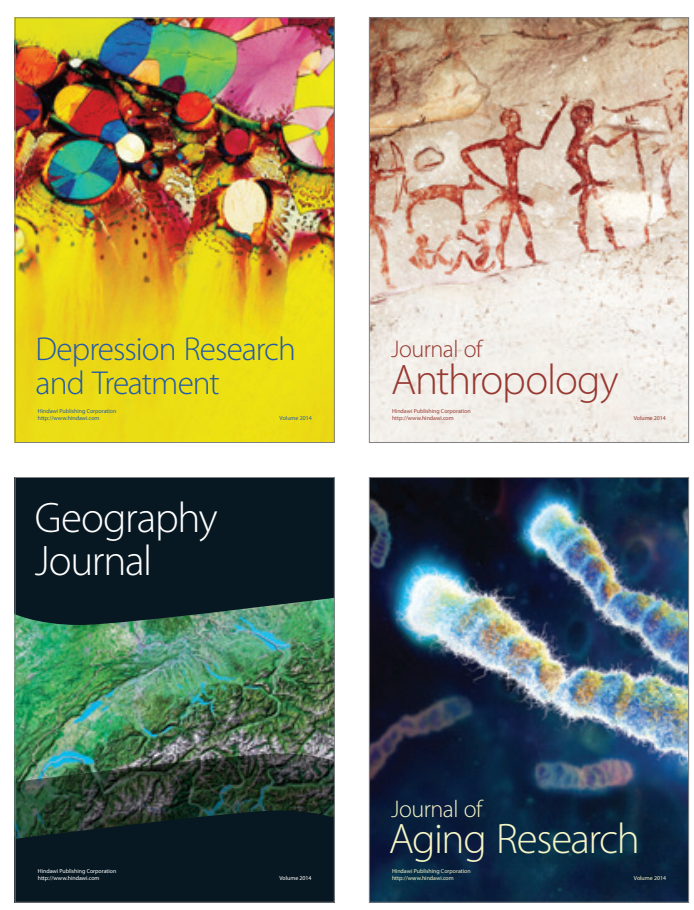

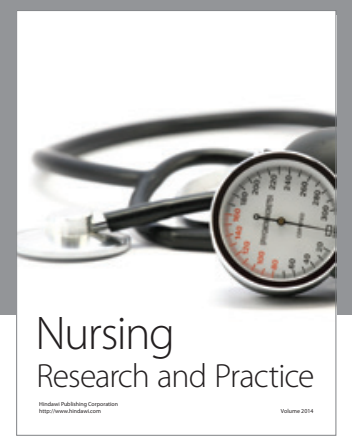

Nursing

Research and Practice

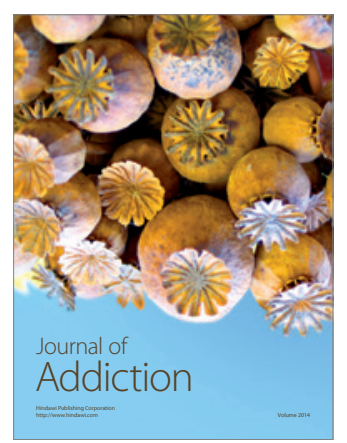

Child Development

Research

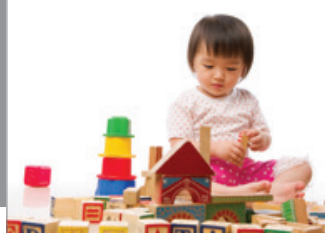

迥
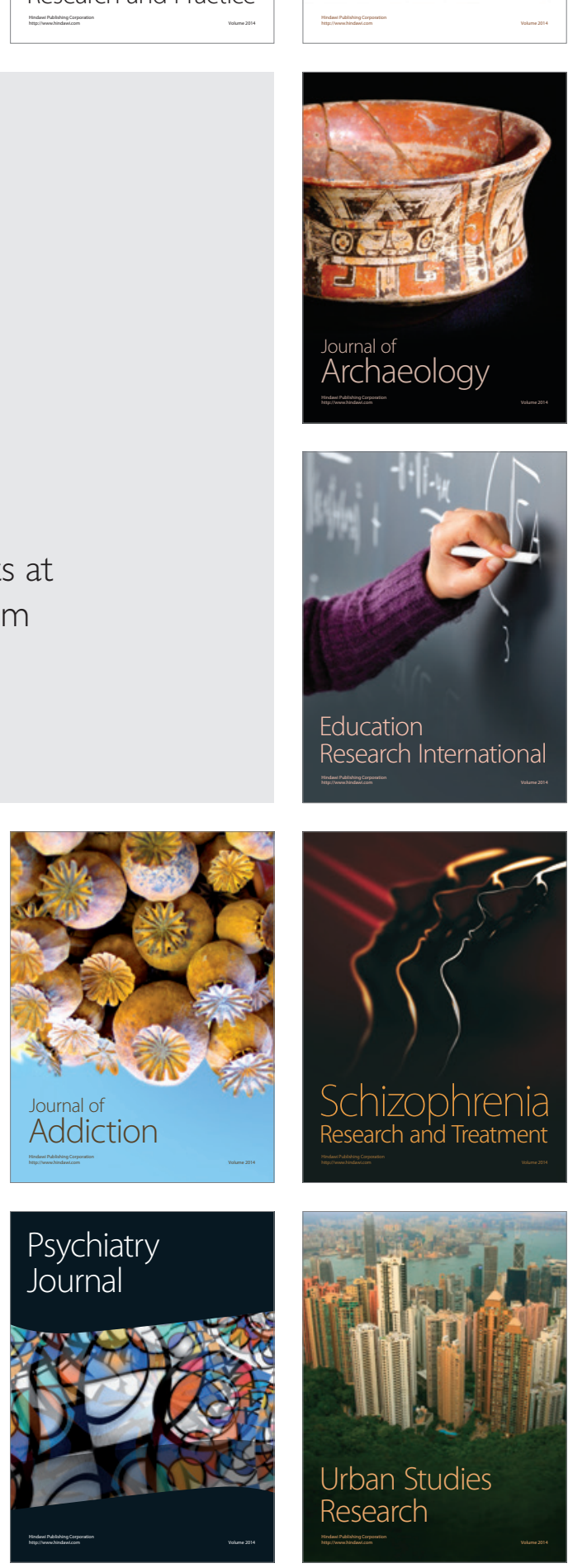